\title{
Characterization of proteome alterations in Phanerochaete chrysosporium in response to lead exposure
}

\author{
Volkan Yıldırım', Servet Özcan², Dörte Becher ${ }^{3}$, Knut Büttner $^{3}$, Michael Hecker $^{3}$, Gülay Özcengiz $^{1 *}$
}

\begin{abstract}
Background: Total soluble proteome alterations of white rot fungus Phanerochaete chrysosporium in response to different doses (25, 50 and $100 \mu \mathrm{M})$ of $\mathrm{Pb}$ (II) were characterized by 2DE in combination with MALDI-TOF-MS.

Results: Dose-dependent molecular response to $\mathrm{Pb}$ (II) involved a total of 14 up-regulated and 21 down-regulated proteins. The induction of an isoform of glyceraldehyde 3-phosphate dehydrogenase, alcohol dehydrogenase class $\mathrm{V}$, mRNA splicing factor, ATP-dependent RNA helicase, thioredoxin reductase and actin required a Pb (II) dose of at least $50 \mu \mathrm{M}$. Analysis of the proteome dynamics of mid-exponential phase cells of $P$. chrysosporium subjected to 50 $\mu \mathrm{M}$ lead at exposure time intervals of 1, 2, 4 and $8 \mathrm{~h}$, identified a total of 23 proteins in increased and 67 proteins in decreased amount. Overall, the newly induced/strongly up-regulated proteins involved in (i) amelioration of lipid peroxidation products, (ii) defense against oxidative damage and redox metabolism, (iii) transcription,

recombination and DNA repair (iv) a yet unknown function represented by a putative protein.

Conclusion: The present study implicated the particular role of the elements of DNA repair, post-tanscriptional regulation and heterotrimeric $\mathrm{G}$ protein signaling in response to $\mathrm{Pb}$ (II) stress as shown for the first time for a basidiomycete.
\end{abstract}

\section{Background}

Heavy metal pollution is a major environmental concern due to its toxic effects through the food chain and its high persistence in the environment [1]. Lead $(\mathrm{Pb})$ is one of the most abundant toxic metal; mining and smelting activities, lead containing paints, paper and pulp, gasoline and explosives as well as the disposal of municipal sewage sludge enriched with $\mathrm{Pb}$ being the main sources of pollution [2]. Possible mechanisms involved in metal-induced oxidative stress were extensively reviewed by Ercal et al. [3]. As a redox-inactive metal, $\mathrm{Pb}$ is known to deplete cells' major antioxidants, thiol-containing antioxidants and enzymes in particular.

The unique oxidative enzyme system of white-rot basidiomycetes is directly involved in complete lignin mineralization and degradation of various xenobiotic compounds as well as dyes [4,5]. Phanerochaete

\footnotetext{
* Correspondence: ozcengiz@metu.edu.tr

'Department of Biological Sciences, Middle East Technical University, Ankara, Turkey

Full list of author information is available at the end of the article
}

chrysosporium is one of the best studied white-rot fungi shown to be very promising for treatment of phenolic effluents from pulp and paper, coal conversion, textile and olive oil industries. This organism is also very effective in biosorbing heavy metal ions from dilute solutions [6-8], with an equilibrium adsorptive capacity order of lead (II) > chromium (III) > copper (II) = cadmium (II) $>$ nickel (II) [9]. Recently, P. chrysosporium was successfully employed for bioremediation of lead-contaminated soil $[10,11]$. It is well-known that tolerance to different metals varies greatly among microorganisms. When the above-mentioned heavy metals were compared for their effects on growth of $P$. chrysosporium, lead was the best tolerated metal in that the concentrations up to $100 \mu \mathrm{M}$ did not interfere with growth in liquid cultures (unpublished). Comparatively, only $5 \mu \mathrm{M}$ of this metal inhibits the growth of S. cerevisiae by approximately 30\% [12].

The concentration level of lead found in wastewaters varies greatly depending on the type of wastewater which is ranging between 0.04 to $0.05 \mathrm{ppm}$ in urban wastewater $[13,14], 0.06$ to $2.60 \mathrm{ppm}$ in industrial 
wastewater [15], $1.27 \mathrm{ppm}$ in metal finishing waste water in particular [16], and 20 to $100 \mathrm{ppm}$ in waste biogas residual slurry [17]. Temporal variability of these concentrations as caused, for example, by rain events or regular daily fluctuations as seen in wastewater treatment plant effluents is to be noted [18].

While the effects of toxic metals on cell physiology can be studied at the level of individual proteins, proteomics has allowed the responses to be studied on a much wider scale $[19,20]$. Regarding eukaryotic microorganisms, heavy metal stress proteomics have been published for S. cerevisiae [21,22], Schizosaccharomyces pombe [23] and Chlamydomonas reinhardtii [24]. Our group reported the first reference proteome map of $P$. chrysosporium along with an analysis of cadmium and copper response in this organism [25]. A total of $80 \mathrm{Cd}$-upregulated and $74 \mathrm{Cu}$-up-regulated protein spots were detected and identified, 34 being common to the stress caused by both metals. Thus the aim of the present study is to determine the dynamic response of $P$. chrysosporium proteome to subtoxic levels of lead.

\section{Results and Discussion}

To investigate the proteome response of $P$. chrysosporium to $\mathrm{Pb}$ (II) exposure we used 2D electrophoresis followed by MALDI-TOF analysis. The cells were exposed either three levels of $\mathrm{Pb}(25,50$ and $100 \mu \mathrm{M})$ for $40 \mathrm{~h}$ or $50 \mu \mathrm{M}$ of $\mathrm{Pb}$ after $40 \mathrm{~h}$ incubation for $1,2,4$ and 8 h. This kind of setup helped us to observe proteome response of $P$. chrysosporium to acute and chronic exposure of $\mathrm{Pb}$ (II). The highest lead concentration employed in this study $(100 \mu \mathrm{M}$; ca $20 \mathrm{ppm})$ is about 8 fold higher than its upper level reported for industrial wastewaters [15].

When subjected to different levels of $\mathrm{Pb}$ (II), a total of 14 up-regulated and 21 down-regulated protein spots were identified. (Table 1 and 2). Among the up-regulated proteins, the proteins common to all three dosages included isocitrate dehydrogenase alpha subunit, UDPglucose pyrophosphorylase, septin family protein (P-loop GTPase), F0F1-type ATP synthase, alpha subunit, GTPase Ran/TC4/GSP1, short-chain acyl-CoA dehydrogenase, polyadenylate-binding protein (RRM superfamily) and $G$ protein beta subunit-like protein. On the other hand, the induction of an isoform of glyceraldehyde 3-phosphate dehydrogenase, alcohol dehydrogenase class V, mRNA splicing factor, ATP-dependent RNA helicase, thioredoxin reductase and actin required $\mathrm{a} \mathrm{Pb}$ (II) dose of at least $50 \mu \mathrm{M}$.

Among the up-regulated proteins, 6 were newly induced. One such protein was mitochondrial F0F1-type ATP synthase, alpha subunit (Figure 1a) which pointed to galvanized energy metabolism under stress. The other one was actin (Figure 1b) constituting a cytoskeleton that plays a pivotal role in many eukaryotic signaling pathways. Actin-induced hyperactivation of the Ras signaling pathway was demonstrated to lead to apoptosis in S. cerevisiae [26]. A septin family protein (P-loop GTPase) was also newly induced in response to $\mathrm{Pb}$ (II) exposure (Figure 1b). Septin family of cytoskeletal proteins with GTPase activity are involved in many processes including membrane dynamics, vesicle trafficking, apoptosis and infection [27]. Ras GTPase [GTPase Ran/ TC4/GSP1 (nuclear protein transport pathway; small G protein superfamily)] was found as a $\mathrm{Cd}$ responsive protein in our previous study [25], providing clue for the existence of Ras signaling pathway in $P$. chrysosporium, a pathway accelerating programmed cell death in $C$. albicans under harsh environmental stress [28]. In the present work, Ras GTPase was detected as a newly expressed protein upon $\mathrm{Pb}$ exposure (Figure 1c), thus providing another evidence for its role in heavy metal stress response.

RNA-binding proteins (RBPs) shuttle between cellular compartments either constitutively or in response to stress and regulate localization, translation, or turnover of mRNAs [29]. Post-transcriptional regulation can also occur through stabilization of mRNAs by specific RBPs in response to certain stimuli. The process of bulk export of mRNAs from nucleus to cytoplasm is highly conserved across eukaryotes. The export-competent mRNP consists of mRNAs and a dozen nucleocytoplasmic shuttling nuclear proteins, including RNA export factors, poly(A)-binding proteins, DEAD-box protein 5 and nucleoporins in yeast [30]. The RNA recognition motif (RRM) domain is by far the most abundant type of eukaryotic RNA-binding motif and besides mRNA binding, RRM domains involve in diverse protein-protein interactions. RBPs have been shown to translocate to the cytoplasm in response to stress. For example, A18 hnRNP, as induced by UV radiation, targets stressactivated transcripts and stimulates translation, thereby increasing survival after genotoxic stress [31]. In the present study, the identified RBPs were a newly-induced polyadenylate-binding protein (RRM superfamily) (Figure 1d) as well as two up-regulated proteins, namely splicing factor RNPS1 (Figure 1e) and ATP-dependent RNA helicase (Figure 1f). Splicing factor RNPS1 is a versatile splicing regulator for a wide variety of alternatively spliced genes and regulates alternative splicing both negatively and positively through interaction with associated factors in vivo [32]. Although their exact mechanism of function remains unclear, several ATP-dependent RNA helicases of the DEAD-box family have been described to be involved in transcription, pre-mRNA splicing, ribosome biogenesis, nuclear export, resolution of inhibitory mRNA secondary structures and translation initiation, RNA degradation and even organelle 
Table 1 Dose-dependent upregulated protein spots in response to $\mathrm{Pb}$ (II)

\begin{tabular}{|c|c|c|c|c|c|c|c|}
\hline \multirow[b]{2}{*}{ KOG Class } & \multirow[b]{2}{*}{$\begin{array}{l}\text { Protein } \\
\text { ID }\end{array}$} & \multirow[b]{2}{*}{ Putative Function } & \multicolumn{3}{|c|}{$\begin{array}{c}\text { Treatment/ } \\
\text { Control Ratio }\end{array}$} & \multirow[b]{2}{*}{$\begin{array}{l}\text { Subcellular } \\
\text { Locations* }\end{array}$} & \multirow[b]{2}{*}{$\begin{array}{l}\text { Multiple } \\
\text { Spots }\end{array}$} \\
\hline & & & $\begin{array}{l}25 \\
\mu \mathrm{M}\end{array}$ & $\begin{array}{c}50 \\
\mu \mathrm{M}\end{array}$ & $\begin{array}{l}100 \\
\mu \mathrm{M}\end{array}$ & & \\
\hline $\begin{array}{l}\text { Amino acid transport and } \\
\text { metabolism }\end{array}$ & 139320a & Isocitrate dehydrogenase, alpha subunit & 5,14 & 5,02 & 4,06 & Mit & 2 \\
\hline \multirow{3}{*}{$\begin{array}{l}\text { Carbohydrate transport and } \\
\text { metabolism }\end{array}$} & 134115 & UDP-glucose pyrophosphorylase & 3,50 & 3,05 & 5,22 & Cyto_nuc & - \\
\hline & 135471 & Septin family protein (P-loop GTPase) & New & New & New & M & - \\
\hline & 132198d & Glyceraldehyde 3-phosphate dehydrogenase & - & New & New & C & 4 \\
\hline Cytoskeleton & $139298 a$ & Actin and related proteins & 1,38 & 11,01 & 1,43 & Cysk & 4 \\
\hline Energy production and conversion & $137299 d$ & FOF1-type ATP synthase, alpha subunit & New & New & New & Mit & 4 \\
\hline General function prediction only & 134635 & mRNA splicing factor & 2,29 & 4,62 & 2,26 & C & - \\
\hline $\begin{array}{l}\text { Intracellular trafficking, secretion, and } \\
\text { vesicular transport }\end{array}$ & 123314 & $\begin{array}{l}\text { GTPase Ran/TC4/GSP1 (nuclear protein transport } \\
\text { pathway), small G protein superfamily }\end{array}$ & New & New & New & C & - \\
\hline Lipid transport and metabolism & 1819 & Short-chain acyl-CoA dehydrogenase & 3,60 & 3,70 & 4,30 & C & - \\
\hline $\begin{array}{l}\text { Posttranslational modification, } \\
\text { protein turnover, chaperones }\end{array}$ & 8527 & Thioredoxin reductase & 2,54 & 3,49 & 4,46 & Mit & - \\
\hline \multirow[t]{2}{*}{ RNA processing and modification } & $123005 a$ & Polyadenylate-binding protein (RRM superfamily) & New & New & New & Cysk & 2 \\
\hline & 126823 & ATP-dependent RNA helicase & 0,97 & 7,89 & 1,86 & Nuc & - \\
\hline $\begin{array}{l}\text { Secondary metabolites biosynthesis, } \\
\text { transport and catabolism }\end{array}$ & $4796 c$ & Alcohol dehydrogenase, class $V$ & - & New & New & C & 4 \\
\hline Signal transduction mechanisms & 10373 & G protein beta subunit-like protein & 3,10 & 3,30 & 4,60 & C & - \\
\hline
\end{tabular}

gene expression [33]. This enzyme was shown to be involved in adaptive response to oxidative stress in Clostridium perfringens [34], heat shock response in Aspergillus fumigatus [35] and various kinds of stress in many plants, including salt response in barley [36], pathogen infection and oxidative stress in transgenic Arabidopsis [37] and salt stress in the halophyte Apocynum venetum [38]. Taken together, up-regulation of above-mentioned proteins in $P$. chrysosporium in response to $\mathrm{Pb}$ stress strongly suggests that these proteins might act in concert to mediate transcriptional and post-tanscriptional regulations in a direction to overcome $\mathrm{Pb}$ toxicity.

An isoform of glyceraldehyde-3-phosphate dehydrogenase (GAPDH) (Figure 1g) was also among newly induced proteins in response to $\mathrm{Pb}$. This extremely abundant glycolytic enzyme has multiple and unrelated functions. GAPDH expression was shown to increase in various organisms during apoptosis induced by a variety of stress factors. Potential role of its nuclear translocation in apoptosis and oxidative stress was proposed to be related with its activity as a DNA repair enzyme or as a nuclear carrier for pro-apoptotic molecules [39]. Different isoforms of GAPDH responding differently to $\mathrm{H}_{2} \mathrm{O}_{2}$ stress have been shown in $S$. pombe [40] and in budding yeast $[41,42]$. In $S$. pombe, peroxide stress signals are transmitted from the Mak2/3 sensor kinases to the Mpr1 histidine-containing phosphotransfer (HPt) protein and finally to the Mcs4 response regulator, which activates a MAP kinase cascade. Morigasaki et al. [43] recently showed that GAPDH plays an essential role in the phosphorelay signaling by physically associating with the Mcs4 response regulator and stress-responsive MAP kinase kinase kinases (MAPKKKs), where its redox-sensitive cysteine residue which is transiently oxidized in response to $\mathrm{H}_{2} \mathrm{O}_{2}$ stress may enhance its association. In Arabidopsis thaliana, the steady-state mRNA level of the cytosolic GAPDH increased when plants were transferred from normal growth condition to heatshock, anaerobiosis, or increased sucrose supply [44] and the enzyme was recently shown to suppress heat shock-induced $\mathrm{H}_{2} \mathrm{O}_{2}$ production and cell death [45].

The induction of redox enzyme thioredoxin reductase was quite expected given its role in the regeneration of reduced thioredoxin (Figure 2a). UDP-glucose is not only a necessary metabolite for cell wall biogenesis, but it is involved in the synthesis of the carbohydrate moiety of glycolipids and glycoproteins [46]. UDP-glucose pyrophosphorylase (Figure $2 \mathrm{~b}$ ) which is under the control of stationary phase transcription factor SigmaB in B. subtilis [47] was shown as a novel salt stress-responsive protein in rice [48]. G-proteinlinked pathways evolved to allow responses to extracellular agonists in eukaryotic cells include those for nutrient sensing, pheromone response and mating, and pathogenesis in fungi [49], however except for the induction of $\mathrm{Cd}$-induced $\mathrm{G}$-protein $\beta$ subunit in fission 
Table 2 Dose-dependent downregulated protein spots in response to $\mathrm{Pb}$ (II)

\begin{tabular}{|c|c|c|c|c|c|c|c|}
\hline \multirow[b]{2}{*}{ KOG Class } & \multirow[b]{2}{*}{ Protein ID } & \multirow[b]{2}{*}{ Putative Function } & \multicolumn{3}{|c|}{$\begin{array}{l}\text { Treatment/ } \\
\text { Control Ratio }\end{array}$} & \multirow[b]{2}{*}{$\begin{array}{l}\text { Subcellular } \\
\text { location* }^{*}\end{array}$} & \multirow[b]{2}{*}{$\begin{array}{l}\text { Multiple } \\
\text { spots }\end{array}$} \\
\hline & & & $\begin{array}{l}25 \\
\mathrm{uM}\end{array}$ & $\begin{array}{l}50 \\
\mathrm{uM}\end{array}$ & $\begin{array}{l}100 \\
\mathrm{uM}\end{array}$ & & \\
\hline \multirow[t]{9}{*}{$\begin{array}{l}\text { Amino acid transport and } \\
\text { metabolism }\end{array}$} & $138721 a$ & $\begin{array}{l}\text { Glutamate/leucine/phenylalanine/valine } \\
\text { dehydrogenases }\end{array}$ & 0,50 & 0,22 & 1,32 & C & 2 \\
\hline & $139320 b$ & Isocitrate dehydrogenase, alpha subunit & 0,12 & 0,02 & 0,01 & Mit & 3 \\
\hline & $139663 \& 138887 a$ & $\begin{array}{l}\text { Methionine synthase II (cobalamin- } \\
\text { independent)-//-aconitate hydratase }\end{array}$ & 0,24 & 0,09 & 0,08 & C & 4 \\
\hline & $139663 \& 138887 b$ & $\begin{array}{l}\text { Methionine synthase II (cobalamin- } \\
\text { independent)-//-aconitate hydratase }\end{array}$ & 0,30 & 0,06 & 0,15 & C & 4 \\
\hline & 139663\&138887C & $\begin{array}{l}\text { Methionine synthase II (cobalamin- } \\
\text { independent)-//-aconitate hydratase }\end{array}$ & 0,14 & 0,00 & 0,05 & C & 4 \\
\hline & 139663\&138887d & $\begin{array}{l}\text { Methionine synthase II (cobalamin- } \\
\text { independent)-//-aconitate hydratase }\end{array}$ & 0,26 & 0,18 & 0,06 & C & 4 \\
\hline & $139663 d$ & $\begin{array}{l}\text { Methionine synthase II (cobalamin- } \\
\text { independent) }\end{array}$ & 0,15 & 0,17 & 0,66 & C & 6 \\
\hline & 139663 e & $\begin{array}{l}\text { Methionine synthase II (cobalamin- } \\
\text { independent) }\end{array}$ & 0,20 & 0,20 & 0,60 & C & 6 \\
\hline & $139663 f$ & $\begin{array}{l}\text { Methionine synthase II (cobalamin- } \\
\text { independent) }\end{array}$ & 0,07 & 0,02 & 0,01 & C & 6 \\
\hline Cytoskeleton & $139298 c$ & Actin and related proteins & 0,59 & 0,16 & 1,15 & Cysk & 4 \\
\hline \multirow[t]{2}{*}{ Energy production and conversion } & 1056 & Zinc-binding oxidoreductase & 0,14 & 0,09 & 0,25 & C & - \\
\hline & 123932 & Fumarate reductase, flavoprotein subunit & 0,14 & 0,07 & 0,34 & C & - \\
\hline Lipid transport and metabolism & 10015 & Acetyl-CoA acetyltransferase & 0,66 & 0,24 & 0,88 & C & 2 \\
\hline \multirow[t]{4}{*}{ NA } & 8290 & hypothetical protein & 0,40 & 0,22 & 0,28 & C & - \\
\hline & $140431 b$ & hypothetical protein & 0,04 & 0,03 & 0,01 & C & 4 \\
\hline & 140431c & hypothetical protein & 0,19 & 0,03 & 0,07 & C & 4 \\
\hline & 140431d & hypothetical protein & 0,52 & 0,22 & 0,11 & C & 4 \\
\hline Posttranslational modification, & 122440 & $\begin{array}{l}\text { Molecular chaperones HSP70/HSC70, } \\
\text { HSP70 superfamily }\end{array}$ & 0,53 & 0,09 & 0,84 & C & 6 \\
\hline protein turnover, chaperones & 131983b & $\begin{array}{l}\text { Molecular chaperones GRP78/BiP/KAR2, } \\
\text { HSP70 superfamily }\end{array}$ & 0,71 & 0,11 & 0,19 & Ext & 2 \\
\hline $\begin{array}{l}\text { Secondary metabolites biosynthesis, } \\
\text { transport and catabolism }\end{array}$ & 8565 & Hydroxysteroid 17-beta dehydrogenase 11 & 0,45 & 0,29 & 1,24 & Mit & - \\
\hline Signal transduction mechanisms & 10895 & $\begin{array}{l}\text { Glycosylphosphatidylinositol-specific } \\
\text { phospholipase C }\end{array}$ & 0,11 & 0,30 & 1,19 & Cyto_nucl & - \\
\hline
\end{tabular}

${ }^{*}$ C; cytoplasmic, Ext; extracellular, Mit; mitochondrial, Nuc; Nuclear, Cysk; cytoskeleton, Cyto_nucl; cytoplasmic_nuclear.

yeast [50], there is scarcity of literature reports on the roles of these pathways in stress response. On the other hand, evidence is accumulating for heterotrimeric $\mathrm{G}$ protein signaling in stress-associated physiological processes in plants. In mature leaves, $G$ proteins transmit signals to molecules, including small GTPases, ion channels, and phospholipases which are the effectors in the responses to various stress conditions, including pathogens, ozone treatment and water deficit [51]. Arabidopsis thaliana with null mutation in the gene encoding $\beta$ subunit of heterotrimeric $\mathrm{G}$ protein was more sensitive to $\mathrm{O}_{3}$ damage than wild-type plants [52]. The newly induced $G$ protein beta subunit-like protein (Figure 2c) demonstrated in our work provided evidence for heterotrimeric $G$ protein signaling under $\mathrm{Pb}$ (II) stress in P. chrysosporium.
Zn-containing alcohol dehydrogenase (Class V), with accession number 4796, gives the highest homology to Cryptococcus neoformans mannitol-1-P-dehydrogenase, a zinc-containing long chain alcohol/polyol dehydrogenase accumulating mannitol as an intracellular osmolyte and stress protectant [53]. Members of this family metabolize a wide variety of substrates, including ethanol, retinol, other aliphatic alcohols, hydroxysteroids, and lipid peroxidation products. The enzyme seemed to undertake one of the major functions to counteract with $\mathrm{Cu}$ toxicity [25] and $\mathrm{Pb}$ toxicity, as revealed by the present study (Figure 2d).

As to the down-regulated proteins, the most drastic effect was the decrease in abundance of certain isoforms of cobalamin-independent methionine synthase. Protein glutathionylation has been increasingly recognized as an 


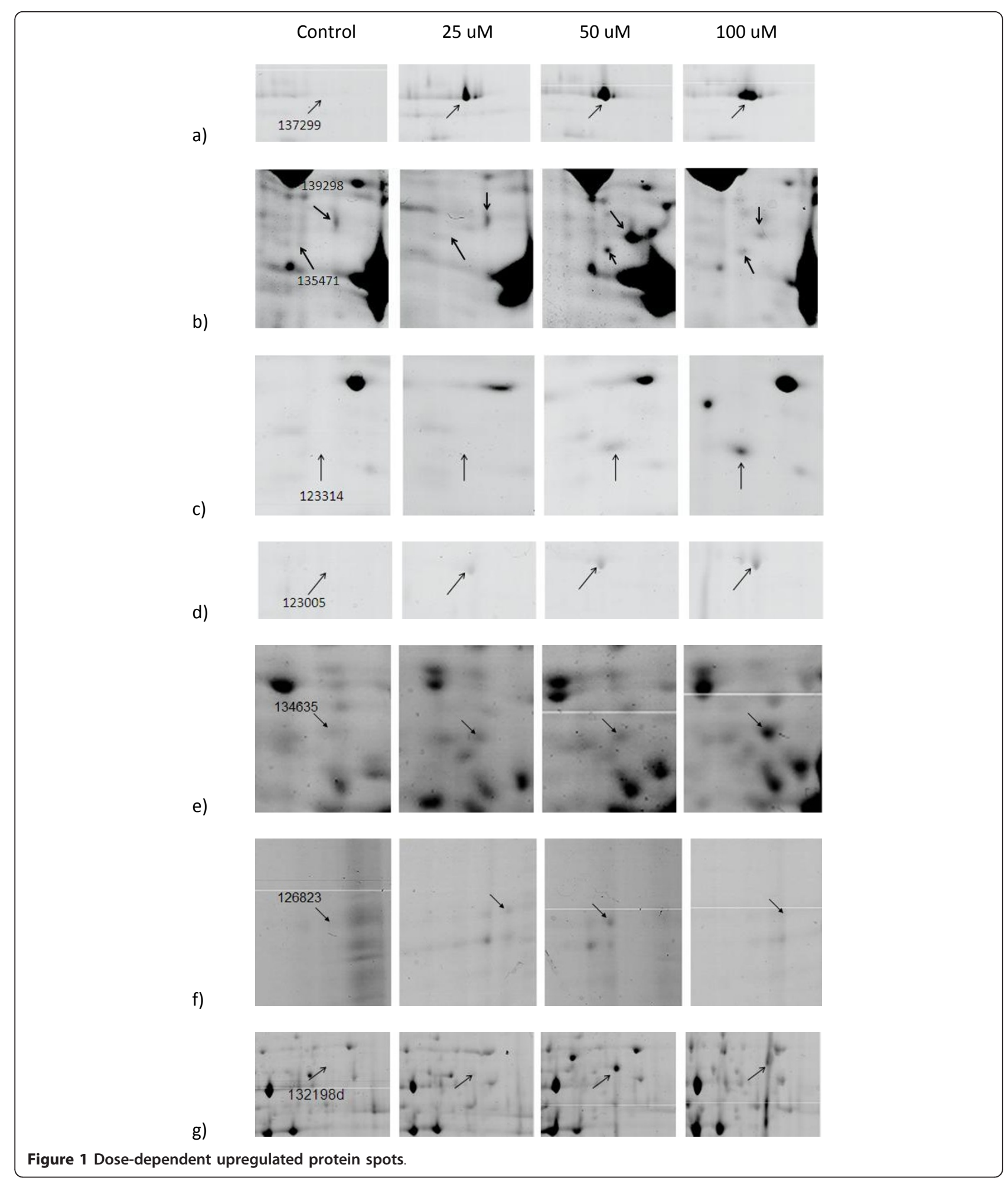

important mode of regulation in eukaryotes and glutathionylation of key proteins involved in protein synthesis leads to inhibition of translation. MetE is so far one of the few proteins in bacteria known to be the most sensitive to oxidative damage. When stressed by an oxidant, glutathionylation of the active site of MetE protects the enzyme from permanent oxidative damage as shown in E. coli [54]. Thus, by turning off MetE in the face of oxidative stress, protein synthesis can be slowed or stopped, freeing cellular resources to be used 


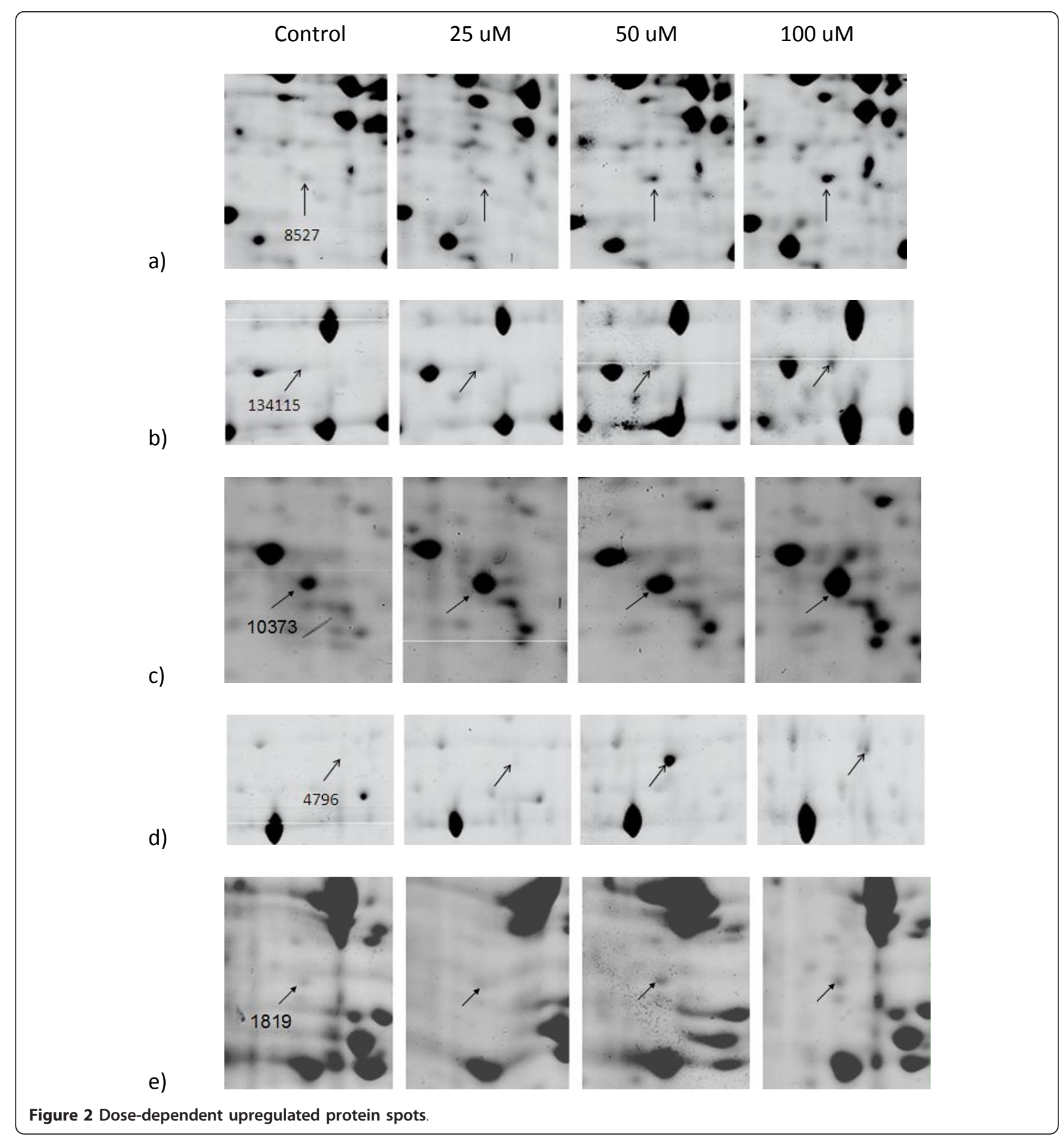

elsewhere. Also, diminished expression of genes encoding enzymes in methionine and cysteine biosynthesis can be interpreted as a mechanism of securing sulfur for production of proteins involved in reductive detoxification, such as thioredoxin and glutathione [55].

Analysis of the proteome dynamics of mid-exponential phase cells of $P$. chrysosporium subjected acute lead exposure identified a total of 88 differentially expressed protein spots, 23 up-regulated and 67 down-regulated
(Table 3 and 4). Regarding the up-regulated ones, seven proteins, namely aldehyde dehydrogenase, alcohol dehydrogenase class V, $60 \mathrm{~S}$ acidic ribosomal protein P0 and particular isoforms of a putative protein, glyoxylate as well as certain isoforms of NAD-dependent malate dehydrogenase and glyceraldehyde-3-phosphate dehydrogenase were newly-induced upon lead exposure. For 17 out of a total of 23 up-regulated ones, the most significant increase was detected after $1 \mathrm{~h}$ exposure. 
Table 3 Time-dependent upregulated protein spots in response to $\mathrm{Pb}$

\begin{tabular}{|c|c|c|c|c|c|c|c|c|}
\hline \multirow[b]{2}{*}{ KOG class } & \multirow[b]{2}{*}{$\begin{array}{l}\text { Protein } \\
\text { ID }\end{array}$} & \multirow[b]{2}{*}{ Putative Function } & \multicolumn{4}{|c|}{$\begin{array}{l}\text { Treatment/Control } \\
\text { ratio }\end{array}$} & \multirow[b]{2}{*}{$\begin{array}{l}\text { Subcellular } \\
\text { location* }\end{array}$} & \multirow[b]{2}{*}{$\begin{array}{c}\text { Multiple } \\
\text { spots }\end{array}$} \\
\hline & & & $1 \mathrm{~h}$ & $2 \mathrm{~h}$ & $4 \mathrm{~h}$ & $8 \mathrm{~h}$ & & \\
\hline \multirow{2}{*}{$\begin{array}{l}\text { Amino acid transport and } \\
\text { metabolism }\end{array}$} & $130118 a$ & Glutamine synthetase & 1,50 & 3,61 & 3,88 & 1,08 & C & 4 \\
\hline & 139663 & Methionine synthase II (cobalamin-independent) & 3,51 & 0,58 & 2,29 & 1,58 & C & 3 \\
\hline \multirow{4}{*}{$\begin{array}{l}\text { Carbohydrate transport and } \\
\text { metabolism }\end{array}$} & 137211 & Dihydroxyacetone kinase/glycerone kinase & 9,99 & 3,50 & 3,37 & 3,93 & C & - \\
\hline & $132198 c$ & Glyceraldehyde 3-phosphate dehydrogenase & 7,40 & 7,00 & 5,20 & 4,80 & C & 5 \\
\hline & 132198d & Glyceraldehyde-3-phosphate dehydrogenase & new & new & new & new & C & 5 \\
\hline & 132198 e & Glyceraldehyde 3-phosphate dehydrogenase & 1,29 & 4,90 & 4,71 & 6,09 & C & 5 \\
\hline \multirow{7}{*}{$\begin{array}{l}\text { Energy production and } \\
\text { conversion }\end{array}$} & 133289 & Aldehyde dehydrogenase & 4,36 & 3,09 & 2,30 & 3,34 & C & - \\
\hline & 134389 & $\begin{array}{l}\text { NADH-dependent flavin oxidoreductase/12- } \\
\text { oxophytodienoate reductase }\end{array}$ & 4,74 & 0,82 & 1,29 & 1,33 & C & - \\
\hline & 138693 & Aldehyde dehydrogenase & new & new & new & new & C & - \\
\hline & $123932 a$ & Fumarate reductase, flavoprotein subunit & 3,54 & 2,39 & 1,37 & 1,87 & C & 2 \\
\hline & $129245 a$ & NAD-dependent malate dehydrogenase & new & new & new & - & Mit & 5 \\
\hline & 133757c & $\begin{array}{l}\text { Glyoxylate/hydroxypyruvate reductase (D-isomer- } \\
\text { specific 2-hydroxy acid dehydrogenase } \\
\text { superfamily) }\end{array}$ & new & new & new & new & C & 3 \\
\hline & $135576 b$ & $\begin{array}{l}\text { Inorganic pyrophosphatase/Nucleosome } \\
\text { remodeling factor, subunit NURF38 }\end{array}$ & 1,24 & 1,34 & 8,02 & 0,84 & Nuc & 4 \\
\hline \multirow[t]{2}{*}{$\begin{array}{l}\text { General function prediction } \\
\text { only }\end{array}$} & 10307 & $\begin{array}{l}\text { 1,4-benzoquinone reductase-like; Trp repressor } \\
\text { binding protein-like/protoplast-secreted protein }\end{array}$ & 0,44 & 0,87 & 13,14 & 4,72 & $C$ & - \\
\hline & 132851 & Glyoxylase & 6,16 & 1,99 & 4,02 & 2,30 & C & - \\
\hline \multirow[t]{3}{*}{ NA } & $140431 a$ & Putative Protein & - & new & new & new & C & 4 \\
\hline & $140431 b$ & Putative Protein & 19,30 & 9,80 & 19,40 & 22,90 & C & 4 \\
\hline & $140431 c$ & Putative Protein & 4,29 & 2,2 & 0,75 & 2,3 & C & 4 \\
\hline $\begin{array}{l}\text { Posttranslational modification, } \\
\text { protein turnover, chaperones }\end{array}$ & 1827 & $\begin{array}{l}20 S \text { proteasome, regulatory subunit alpha type } \\
\text { PSMA6/SCL1 }\end{array}$ & 4,60 & 2,20 & 2,10 & 2,70 & Mit & 2 \\
\hline $\begin{array}{l}\text { RNA processing and } \\
\text { modification }\end{array}$ & 8607 & Splicing factor RNPS1, SR protein superfamily & 3,32 & 3,12 & 0,95 & 3,5 & Cyt_Nuc & - \\
\hline \multirow{2}{*}{$\begin{array}{l}\text { Secondary metabolites } \\
\text { biosynthesis, transport and } \\
\text { catabolism }\end{array}$} & $4796 d$ & Alcohol dehydrogenase, class $V$ & new & new & new & new & C & 4 \\
\hline & 127894 & $\begin{array}{l}\text { Zinc-containing alcohol dehydrogenase } \\
\text { superfamily }\end{array}$ & 5,21 & 3,22 & 5,32 & 6,55 & C & - \\
\hline $\begin{array}{l}\text { Translation, ribosomal } \\
\text { structure and biogenesis }\end{array}$ & 130203 & 605 acidic ribosomal protein P0 & new & new & new & new & C & - \\
\hline
\end{tabular}

${ }^{*}$ C; cytoplasmic, Ext; extracellular, Mit; mitochondrial, Nuc; Nuclear, Cysk; cytoskeleton, Cyto_nuc; cytoplasmic_nuclear.

Among the up-regulated spots identified, "energy production and conversion" proteins constituted the major KOG class as was found by Garcia-Leiro [56] in an analysis of oxidative stress response of Kluyveromyces lactis.

Although $\mathrm{Pb}$ (II) is not a redox active metal ion, it is known to cause oxidative stress resulting in increased production of reactive oxygen species (ROS) inducing lipid peroxidation $[57,58]$. There were several newly induced/ strongly up-regulated proteins involved in amelioration of lipid peroxidation products, namely zinc-containing alcohol dehydrogenase, glyceraldehyde-3-phosphate dehydrogenase, glyoxylate/hydroxypyruvate reductase (Figure 3a) and two different aldehyde dehydrogenases (ALDH; Figure 3c) detected after $1 \mathrm{~h}$ exposure. NAD-dependent malate dehydrogenase (MDH; Figure $3 \mathrm{~b})$, on the other hand, is a very well known up-regulated component of different stress conditions in various organisms. It provides protection against oxidative damage caused by $\mathrm{Zn}$ in $E$. coli through the action of oxaloacetate [59]. In the fission yeast, $\mathrm{MDH}$ was one of the component core environmental stress response (CESR) as determined by transcriptional profiling, proteomic and metabolomic analysis $[40,50]$. The other components of CESR included zincbinding dehydrogenases, serine/threonine protein kinase, 
Table 4 Time-dependent downregulated protein spots in response to $\mathbf{P b}$

\begin{tabular}{|c|c|c|c|c|c|c|c|c|}
\hline \multirow[b]{2}{*}{ KOG Class } & \multirow[b]{2}{*}{$\begin{array}{l}\text { Protein } \\
\text { ID }\end{array}$} & \multirow[b]{2}{*}{ Putative Function } & \multicolumn{4}{|c|}{$\begin{array}{l}\text { Treatment/control } \\
\text { ratio }\end{array}$} & \multirow[b]{2}{*}{$\begin{array}{l}\text { Subcellular } \\
\text { Location* }\end{array}$} & \multirow[b]{2}{*}{$\begin{array}{l}\text { Multiple } \\
\text { spots }\end{array}$} \\
\hline & & & $1 \mathrm{~h}$ & $2 \mathrm{~h}$ & $4 \mathrm{~h}$ & $8 \mathrm{~h}$ & & \\
\hline \multirow{8}{*}{$\begin{array}{l}\text { Amino acid transport and } \\
\text { metabolism }\end{array}$} & 137931 & Glycine/serine hydroxymethyltransferase & 0,56 & 0,27 & 0,19 & 0,42 & C & 3 \\
\hline & 1542 & 3-isopropylmalate dehydrogenase & 0,39 & 0,42 & 0,26 & 0,39 & C & - \\
\hline & 10011 & $\begin{array}{l}\text { 3-isopropylmalate dehydratase (aconitase } \\
\text { superfamily) }\end{array}$ & 0,15 & 0,55 & 0,14 & 0,18 & Cysk & - \\
\hline & 125842 & $\begin{array}{l}\text { Lysine-ketoglutarate reductase/saccharopine } \\
\text { dehydrogenase }\end{array}$ & 0,43 & 0,17 & 0,08 & 0,33 & C & - \\
\hline & 131837 & Oxoprolinase & 0,56 & 0,32 & 0,31 & 0,24 & C & - \\
\hline & 134775 & Glutamine amidotransferase/cyclase & 0,53 & 0,67 & 0,59 & 0,26 & C & - \\
\hline & 138721 & $\begin{array}{l}\text { Glutamate/leucine/phenylalanine/valine } \\
\text { dehydrogenases }\end{array}$ & 0,84 & 0,35 & 0,23 & 0,34 & C & 2 \\
\hline & 139663 & Methionine synthase II (cobalamin-independent) & 0,25 & 0,36 & 0,05 & 0,17 & C & 5 \\
\hline \multirow{7}{*}{$\begin{array}{l}\text { Carbohydrate transport and } \\
\text { metabolism }\end{array}$} & 8743 & Inositol monophosphatase & 0,12 & 0,04 & 0,06 & 0,39 & C & - \\
\hline & 10433 & Transketolase & 0,92 & 0,89 & 0,89 & 0,18 & C & - \\
\hline & 133884 & Glycolipid transfer protein & 0,04 & 1,12 & 0,39 & 0,27 & C & - \\
\hline & 137623 & Phosphoglucomutase & 1,54 & 0,35 & 0,17 & 1,07 & C & - \\
\hline & $122435 c$ & 3-phosphoglycerate kinase & 0,95 & 0,31 & 0,24 & 1,59 & C & 3 \\
\hline & $3052 a$ & Mannose-6-phosphate isomerase, type II & 0,44 & 0,54 & 0,60 & 0,29 & Cysk & 2 \\
\hline & $3052 b$ & Mannose-6-phosphate isomerase, type II & 0,91 & 0,44 & 0,18 & 0,32 & Cysk & 2 \\
\hline $\begin{array}{l}\text { Coenzyme transport and } \\
\text { metabolism }\end{array}$ & 10308 & S-adenosylhomocysteine hydrolase & 0,67 & 0,64 & 0,30 & 0,56 & C & - \\
\hline Cytoskeleton & 139298 & Actin and related proteins & 0,30 & 0,37 & 0,07 & 0,11 & Cysk & 4 \\
\hline Defense mechanism & 10742 & N-6 Adenine-specific DNA methylase & 1,05 & 0,6 & 0,32 & 0,19 & Mit & - \\
\hline \multirow[t]{13}{*}{$\begin{array}{l}\text { Energy production and } \\
\text { conversion }\end{array}$} & 912 & $\begin{array}{l}\text { Kynurenine 3-monooxygenase and related } \\
\text { flavoprotein monooxygenases }\end{array}$ & 0,78 & 0,41 & 0,19 & 0,20 & Ext & - \\
\hline & 1350 & Aldehyde dehydrogenase & 0,45 & 0,34 & 0,36 & 0,29 & C & - \\
\hline & 132162 & NAD-dependent malate dehydrogenase & 0,00 & 0,37 & 0,55 & 0,51 & C & - \\
\hline & 132918 & Sulfide:quinone oxidoreductase/flavo-binding protein & 0,85 & 0,49 & 0,22 & 0,55 & Mit & - \\
\hline & 134368 & Vacuolar H+-ATPase V1 sector, subunit E & 0,29 & 0,67 & 0,32 & 1,98 & Nuc & - \\
\hline & 135659 & NADP+-dependent malic enzyme & 1,13 & 0,72 & 0,18 & 1,18 & Mit & - \\
\hline & 140211 & $\begin{array}{l}\text { Glyoxylate/hydroxypyruvate reductase (D-isomer- } \\
\text { specific 2-hydroxy acid dehydrogenase superfamily) }\end{array}$ & 1,51 & 0,51 & 0,29 & 0,33 & C & - \\
\hline & $123932 b$ & Fumarate reductase, flavoprotein subunit & 1,21 & 0,85 & 0,60 & 0,10 & C & 2 \\
\hline & $131257 a$ & $\begin{array}{l}\text { NADH-ubiquinone oxidoreductase, NDUFS1/75 kDa } \\
\text { subunit }\end{array}$ & 0,91 & 0,88 & 0,42 & 0,21 & C & 3 \\
\hline & 131879a & Dihydrolipoamide dehydrogenase & 0,62 & 0,52 & 0,26 & 0,80 & C & 2 \\
\hline & $133924 a$ & Aldehyde dehydrogenase & 0,65 & 0,49 & 0,26 & 0,61 & C & 2 \\
\hline & $133924 b$ & Aldehyde dehydrogenase & 0,31 & 0,48 & 0,28 & 0,55 & C & 2 \\
\hline & $563 a$ & Pyruvate dehydrogenase $\mathrm{E} 1$, alpha subunit & 1,33 & 0,28 & 0,27 & 0,28 & Mit & 2 \\
\hline \multirow[t]{2}{*}{ General function prediction only } & 3442 & Predicted NAD-dependent oxidoreductase & 0,30 & 0,22 & 0,54 & 0,50 & C & - \\
\hline & 132767b & Serine/threonine protein kinase, active site & 0,55 & 0,85 & 0,55 & 0,27 & Mit & 2 \\
\hline \multirow[t]{2}{*}{ Lipid transport and metabolism } & 511 & Enoyl-CoA hydratase & 1,04 & 0,74 & 0,14 & 0,96 & C & - \\
\hline & 10355b & Mevalonate pyrophosphate decarboxylase & 0,73 & 0,36 & 0,24 & 0,48 & Mit & 2 \\
\hline \multirow{5}{*}{$\begin{array}{l}\text { Posttranslational modification, } \\
\text { protein turnover, chaperones }\end{array}$} & 361 & $26 \mathrm{~S}$ proteasome regulatory complex, ATPase RPT3 & 0,25 & 0,17 & 0,06 & 0,05 & Nuc & - \\
\hline & 1324 & Molecular co-chaperone STI1 & 1,02 & 0,68 & 0,01 & 1,11 & C & - \\
\hline & 1846 & $\begin{array}{l}\text { Chaperonin complex component, TCP-1 beta } \\
\text { subunit (CCT2) }\end{array}$ & 0,79 & 0,85 & 0,46 & 0,28 & C & - \\
\hline & 5061 & Dipeptidyl aminopeptidase & 1,06 & 1,07 & 0,99 & 0,29 & Ext & 2 \\
\hline & 8527 & Thioredoxin reductase & 0,27 & 0,45 & 0,22 & 0,31 & Mit & - \\
\hline
\end{tabular}


Table 4 Time-dependent downregulated protein spots in response to $\mathrm{Pb}$ (Continued)

\begin{tabular}{|c|c|c|c|c|c|c|c|c|}
\hline & 130274 & Glutathione peroxidase & 0,33 & 0,77 & 1,10 & 0,19 & C & - \\
\hline & 131571 & $\begin{array}{l}\text { Protein disulfide isomerase (prolyl 4-hydroxylase } \\
\text { beta subunit) }\end{array}$ & 0,91 & 0,08 & 0,74 & 0,06 & Ext & - \\
\hline & 133185 & 26S proteasome regulatory complex, ATPase RPT1 & 0,31 & 0,34 & 0,07 & 0,04 & Nuc & - \\
\hline & 133717 & $\begin{array}{l}20 \text { s proteasome, regulatory subunit alpha type } \\
\text { PSMA4/PRE9 }\end{array}$ & 0,30 & 0,62 & 0,82 & 0,73 & Mit & - \\
\hline & 134073 & $\begin{array}{l}\text { Chaperonin complex component, TCP-1 zeta } \\
\text { subunit (CCT6 }\end{array}$ & 0,70 & 0,42 & 0,14 & 0,10 & C & - \\
\hline & 139500 & Multifunctional chaperone (14-3-3 family) & 0,27 & 0,38 & 0,20 & 0,47 & Nuc & - \\
\hline & 10340a & $\begin{array}{l}\text { HSP70(putative ortholog to S. cerevisiae Heat shock } \\
\text { protein homolog SSE1 (Chaperone protein MSI3) }\end{array}$ & 0,66 & 0,54 & 0,06 & 0,64 & C & 2 \\
\hline & $10340 b$ & $\begin{array}{l}\text { HSP70(putative ortholog to S. cerevisiae Heat shock } \\
\text { protein homolog SSE1 (Chaperone protein MSI3) }\end{array}$ & 0,34 & 0,15 & 0,20 & 0,26 & C & 2 \\
\hline \multirow{2}{*}{$\begin{array}{l}\text { Secondary metabolites } \\
\text { biosynthesis, transport and } \\
\text { catabolism }\end{array}$} & 133231 & Predicted dehydrogenase & 0,26 & 0,53 & 0,16 & 0,10 & C & - \\
\hline & $4796 b$ & Alcohol dehydrogenase, class V & 0,61 & 0,31 & 0,17 & 0,07 & C & 4 \\
\hline \multirow{3}{*}{$\begin{array}{l}\text { Translation, ribosomal structure } \\
\text { and biogenesis }\end{array}$} & 3216 & Prolyl-tRNA synthetase & 0,80 & 0,60 & 0,51 & 0,12 & C & - \\
\hline & 6570 & Mitochondrial translation elongation factor Tu & 0,61 & 0,59 & 0,16 & 0,76 & Mit & - \\
\hline & 10819 & Elongation factor 2 & 1,27 & 0,65 & 0,15 & 0,14 & C & - \\
\hline
\end{tabular}

${ }^{*}$ C; cytoplasmic, Ext; extracellular, Mit; mitochondrial, Nuc; Nuclear, Cysk; cytoskeleton, Cyto_nucl; cytoplasmic_nuclear.

G-protein beta subunit, quinone oxidoreductase, flavin oxidoreductase, protein with RNA recognition motif and short chain dehydrogenase, all were found to be up-regulated in P. chrysosporium cells in our former [25] and present study. Hot pepper transcriptome profiling under cold stress [60] proteomic analysis of $\mathrm{Cd}$ response in marine alga Nannochloropsis oculata [61] DNA microarray and quantitative RT-PCR analyses in Corynebacterium glutamicum under oxygen deprivation [62], analysis of a metabolic network in Pseudomonas fluorescens exposed to oxidative stress [63] and transcriptomic analysis of $\mathrm{Al}$ stress in roots of Arabidopsis thaliana [64] were among other studies consistently detecting MDH involvement. As discussed by the latter authors, the burst of ROS generated by $\mathrm{Al}$ had to enhance the generation of NADPH to maintain a high ratio of reduced antioxidants.

In the present study, two different ALDHs with the protein IDs of 133289 and 138693 were found to display a biphasic up-regulation (at $1 \mathrm{~h}$ and $8 \mathrm{~h}$ ) upon $\mathrm{Pb}$ treatment (Figure 3c). ALDH superfamily enzymes and their pathophysiological significance was recently reviewed by Marchitti et al. [65]. Induction of ALDH in response to oxidative stress was demonstrated also in bacteria, e.g. Pseudomonas aeruginosa [66] and yeast [67]. As to the plants, overexpression of ALDH3 genes in A. thaliana confers tolerance to various abiotic stress conditions and protects plants against lipid peroxidation $[68,69]$.

The expression of remarkably many genes encoding proteins and enzymes involved in defense from oxidative damage and redox metabolism is stimulated under a range of stress conditions. Examples of such genes include catalase, thioredoxin, glutaredoxin, genes encoding enzymes possibly involved in detoxification such as glyoxylase and dihydroxyacetone kinase, and numerous oxidoreductases that may be involved in metabolism of oxidized biomolecules or in adjusting redox metabolism to provide sufficient NADPH for detoxification. Dihydroxyacetone kinase/glycerone kinase (DAK) was induced in $P$. chrysosporium $1 \mathrm{~h}$ after $\mathrm{Pb}$ administration (Figure 3d). Its relation with salt stress [70], heat stress [71], osmotic stress [72], oxidative stress [73], starvation [74] and cadmium stress [21] was well documented. Glyoxylase system detoxifying glyoxal, methylglyoxal and other physiological alpha-oxoaldehydes formed by lipid peroxidation is a component of stress response, as shown for yeasts [75,76], various plants [77-79], a parasitic nematode [80] and in a basidiomycete, as shown by our study (Figure 3e).

Inorganic phosphatase constituties NURF-38 subunit of the ATP-dependent Nucleosome Remodeling Factor complex (NURF) which was initially identified in Drosophila and then in yeast and vertebrates [81,82]. The complex, when targeted onto chromatin, affects major DNA-dependent processes including transcription, DNA repair and recombination. Thus, our finding that inorganic pyrophosphatase/nucleosome remodeling factor NURF38 is induced by a factor of 8 upon 4 h lead exposure pointed to its role in responding to metal toxicity in P. chrysosporium (Figure $3 \mathrm{f}$ ). The $60 \mathrm{~S}$ acidic ribosomal protein P0 was one of the newly-induced component of $\mathrm{Pb}$ (II)-stressed proteome. This protein plays an essential role by docking and forming the tip of the 


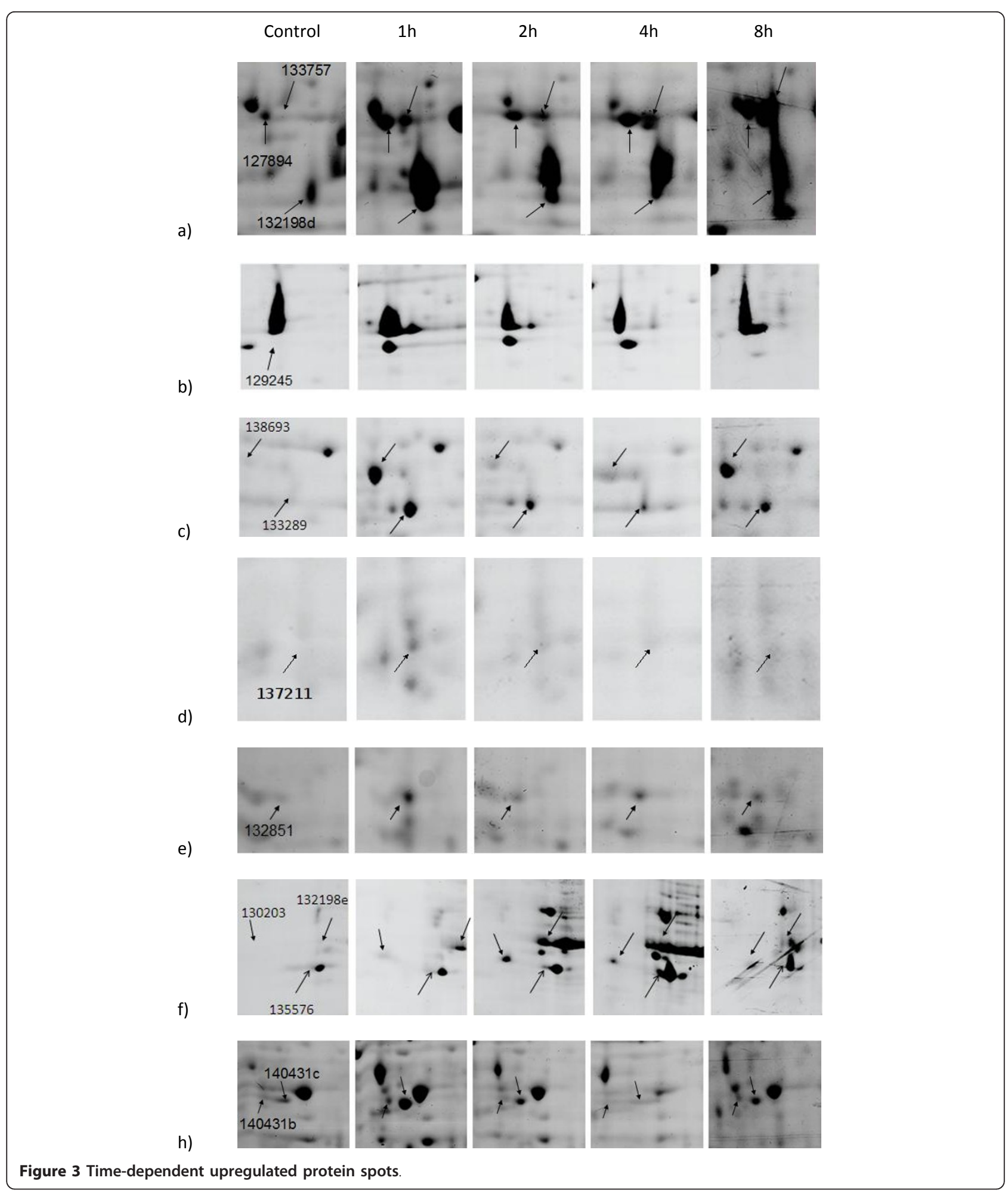

whole eukaryotic ribosomal "stalk" complex [83]. Unlike the typical ribosomal proteins, P0 appears to have multiple functions in the cell. By overexpressing Drosophila P0 in E. coli, Yacoub et al. [84] demonstrated that P0 contained 5' APE activity distinct from the 3' AP lyase activity associated with Drosophila rpS3 and also exhibited nuclease activity against both double and singlestranded DNA. The authors also reported that the protein is located in both nucleus and ribosomes. Recently, this protein was shown to be upregulated in 
Ras-transformed NIH3T3 cells [85] and Jurkat cells during heat stress-induced apoptosis [86]. Additionally, when the $S$. pombe cells challenged with oxidative stress, $60 \mathrm{~S}$ ribosomal protein P0 was among differentiallyexpressed ones though its induction ratio was only 1.6 [40] (Figure 3f).

Being consistent with our former report on $\mathrm{Cu}$ and $\mathrm{Cd}$ response of the organism [25], the downregulated proteins included some redox enzymes and certain molecular chaperons like HSP70, protein disulfide isomerase and chaperonin complex components.

Bacteria and fungi are among the first components of the biota in ecosystems affected by toxic pollutants including heavy metals. Their relatively small size and simplicity make them particularly attractive models for environmental proteomics [18]. The data obtained from the analysis of proteomes of such organisms help to gain insight into underlying mechanisms of toxicity which is of great value from the basic sciences pointview. Besides, the subtle changes detected in the level of individual proteins in response to environmental stressors lead to the discovery of biomarkers of exposure and also provide an opportunity to genetically engineer such microbes to express higher levels of specific proteins (e. g. DNA repair proteins), thereby conferring higher tolerance to increasing concentrations of heavy metals and potentiate bioremediation $[87,88]$. Our studies are under way to obtain complete coverage of the lead-induced stress proteome of $P$. chrysosporium, hence identifying all possible ecotoxicological biomarkers as well as targets for improved lead bioaccumulation.

The apoptotic machinery in fungi was recently reviewed by Sharon et al. [89]. Among fungi, apoptosis has only been studied in detail in S. cerevesiae. Filamentous fungal species are poorly analyzed for functions of the apoptosis-related genes and although homologs of some apoptotic genes could be identified in fungal genomes analyzed, to date only a few genes have been functionally analyzed. A better understanding of fungal apoptotic networks for identification of paralogs and putative homologs of apoptosis as compared to those of high eukaryotes is required which is possible through findings from more fungal species. As reported by Lorin et al. [90] for the filamentous fungus Podospora anserina, compensatory induction of an alternative oxidase (AOX) provides a decreased production of ROS and a striking increase in lifespan. In the present research, the elements like actin known to induce hyperactivation of the Ras signaling pathway, septin family protein (P-loop GTPase) functioning in many processes including apoptosis, Ras GTPase of acceleration of programmed cell death are identified for the first time in a multicellular fungus and expected to contribute to the knowledge on stress-induced apoptosis in fungi. When exposed to lead stress, the elements of stress tolerance and initiation of apoptotic cell death counteracted while the cells of $P$. chrysosporium kept on growing. On the other hand, our findings on induction/upregulation of certain catabolic enzymes and mitochondrial F0F1-type ATP synthase might provide support for an intrinsic and mitochondrial nature of the apostatic response in fungi and fit to the generally accepted view that apoptosis requires energy as it is a highly regulated process involving a number of ATP-dependent steps [91].

\section{Conclusion}

The present study draws attention particularly to the up-regulated elements of apoptosis, DNA repair, posttanscriptional regulation and heterotrimeric $G$ protein signaling as shown for the first time for a metal-stressed basidiomycete. DNA-binding response regulator(s) mediating stress response in $P$. chrysosporium, like Yap1p TF and Yap2p TF of S. cerevisiae [92], Sty1p-activated Atf1p and Pap1p TF of the fission yeast $[50,93]$ and Cap1p TF of Candida albicans [76] remains to be identified through further analysis.

\section{Materials and methods \\ Culture conditions}

P. chrysosporium (ATTC 24725) spores were separated from Sabaroud Dextrose agar slant surfaces by scrapping, homogenized and suspended in sterile distilled water. A spore suspension was prepared to contain 2.5 $\times 10^{6}$ spores. $\mathrm{mL}^{-1}$ at an absorbance of 0.5 at $650 \mathrm{~nm}$ using a Shimadzu UV-1208 spectrophotometer. The suspension was then transferred into a $250 \mathrm{~mL}$ Erlenmayer flasks each containing $150 \mathrm{ml}$ of the growth medium described by Prouty [94] which was composed, in g. $\mathrm{L}^{-1}$, of glucose, 10; $\mathrm{KH}_{2} \mathrm{PO}_{4}, 2 ; \mathrm{MgSO}_{4}, 0.5 ; \mathrm{CaCl}, 0.1$; $\mathrm{NH}_{4} \mathrm{Cl}, 0.12$ and thiamine, 0.001 and adjusted to a $\mathrm{pH}$ of 4.5. The cultures were incubated for $40 \mathrm{~h}$ at $200 \mathrm{rpm}$ in a rotary shaker at $35^{\circ} \mathrm{C}$. When the growth was terminated at $40^{\text {th }} \mathrm{h}$, the cultures were still in exponential growth.

For proteomic characterization of the lead response, the cells of $P$. chrysosporium were grown in minimal media containing different levels of lead $(25,50$ and 100 $\mu \mathrm{M} \mathrm{Pb}\left(\mathrm{NO}_{3}\right)_{2}$, respectively) for $40 \mathrm{~h}$ till they reached mid-exponential phase and they were harvested by filtration, washed twice with distilled water and stored at $-20^{\circ}$ $C$ for the extraction of proteins. As a parallel setup, $P$. chrysosporium cells were grown on minimal media for $40 \mathrm{~h}$ till they reached mid-exponential phase and then subjected to $50 \mu \mathrm{M}$ lead for $1,2,4$ and $8 \mathrm{~h}$ to investigate the effect of duration of temporal $\mathrm{Pb}$ (II) exposure on P. chrysosporium proteome. For both cases, a control sample, without lead exposure, was harvested at $40^{\text {th }} \mathrm{h}$ of the growth. 


\section{Protein Extraction}

After crushing the cells with liquid nitrogen, TCA-acetone extraction was performed as in Damerval et al. [95]. After breaking a $500 \mathrm{mg}$ of harvested mycelium in liquid nitrogen, $5 \mathrm{~mL}$ of $10 \%$ trichloroacetic acid in acetone containing $0.07 \% \beta$-mercaptoethanol was added and vortexed, then incubated at $-20^{\circ} \mathrm{C}$ for $45 \mathrm{~min}$ and centrifuged at $15000 \mathrm{~g}$ for $15 \mathrm{~min}$. The supernatant was decanted and the pellet was resuspended in $5 \mathrm{~mL}$ of acetone containing $0.07 \% \beta$-mercaptoethanol which was then incubated at $-20{ }^{\circ} \mathrm{C}$ for $1 \mathrm{~h}$ (mixed every $15 \mathrm{~min}$ intervals by vortexing) and recentrifuged. The supernatant was discarded, the remaining pellet was vacuumdried and stored as a powder at $-20^{\circ} \mathrm{C}$. The modified Bradford assay [96] was used to determine protein concentrations.

\section{DE}

2D gels of the harvested cells were run in duplicates for control and each treatment. Isoelectric focusing was performed in $18 \mathrm{~cm}$ linear IPG-strips ( $\mathrm{pH}$ range 3-10, Biorad, Hercules, CA, USA). IPG strips were passively rehydrated by applying $300 \mu$ of rehydration buffer containing $8 \mathrm{M}$ urea, $2 \mathrm{M}$ thiourea, 1\% w/v CHAPS, $20 \mathrm{~mm}$ DTT and $0,5 \% \mathrm{v} / \mathrm{v}$ ampholyte $3-10$ with $300 \mu \mathrm{g}$ protein sample for $16 \mathrm{~h}$. Isoelectric focusing was performed with the Protean IEF Cell unit (Biorad, Hercules, CA, USA) employing a total of $80000 \mathrm{Vh}$. After consecutive equilibration of the gels in solutions containing DTT and iodoacetamide as suggested by Görg et al. [97], the separation in the second dimension was done in polyacrylamide gels of $12.5 \% \mathrm{~T}$ and $2.6 \% \mathrm{C}$ on the Biorad Protean Xii electrophoresis system (Biorad, Hercules, CA, USA) by applying $2 \mathrm{~W}$ per gel. Gels were stained with colloidal Coomassie blue [98].

\section{Image analysis}

Coomassie stained gels were digitized by using an HP scanner. Spot pattern analyses were accomplished by using the 2D image analysis software Delta2D version 3.3 (Decodon, Germany). Of the proteins found differentially expressed in $\mathrm{Pb}$ (II)-exposed cells, only those showing at least 3 fold difference in abundance were selected and subjected to MALDI-TOF analysis. To correct the quantitative variability, the spot volumes were normalized as a percentage of the total volume in all of the spots in the gel. SDs of the spot intensities from the two replicates were in the range of $20 \%$.

\section{Protein identification}

The identifications were accomplished by mass spectrometry according to established protocols. Briefly, protein spots were excised from stained 2D gels, destained and digested with trypsin (Promega, Madison, WI, USA) and for extraction of peptides, the gel pieces were covered with $60 \mu \mathrm{l} 0.1 \%$ trifluoroacetic acid in $50 \% \mathrm{CH}_{3} \mathrm{CN}$ and incubated for $30 \mathrm{~min}$ at $40^{\circ} \mathrm{C}$. Peptide solutions were mixed with an equal volume of saturated $\alpha$-cyano-3hydroxycinnamic acid solution in 50\% acetonitrile- $0.1 \%$ trifluoroacetic acid (v/v) and applied to a sample plate for MALDI-TOF-MS. Mass analyses were carried out on the Proteome-Analyzer 4700 (Applied Biosystems, Foster City, CA, USA). The three most abundant peptides in each MS spectrum were chosen for MS/MS experiment. The resulting sequence data were included for the database search to increase the reliability of protein identification. Mass accuracy was usually in the range between 10 and $30 \mathrm{ppm}$.

\section{Database searches}

Amino acid sequences for $P$. chrysosporium proteins were obtained from organism's genome project [Joint Genome Institutes (JGI)] web site [99]. PMF and MS/ MS data was searched in the P. chrysosporium data with the aid of MASCOT software [100]. The searches considered oxidation of methionine and modification of cysteine by carbamidomethylation as well as partial cleavage leaving one internal cleavage site. Of the results given by the MASCOT software, those having a probability score value higher than 53 were considered for successful protein identification. To find out putative functions, protein accession numbers of the identified spots were searched in the JGI website for P. chrysosporium. For the identified proteins, the functional classification was made by consulting to the functional categories list contained in the same website.

Protein subcellular localization predictions were obtained from WoLF PSORT web server [101].

\footnotetext{
Author details

'Department of Biological Sciences, Middle East Technical University, Ankara, Turkey. ${ }^{2}$ Department of Biology, Erciyes University, Kayseri, Turkey. ${ }^{3}$ Institut für Mikrobiologie, Ernst-Moritz Arndt-Universität Greifswald, Greifswald, Germany.
}

\section{Authors' contributions}

VY carried out the 2DE experiments for time dependent $\mathrm{Pb}$ exposure studies. SÖ carried out the 2DE experiments for dose dependent $\mathrm{Pb}$ exposure studies. DB carried out the mass spectrometry analyses and protein identifications. KB participated in the optimization of 2DE protocol for $\mathrm{P}$. chrysosporium. MH participated in the design of the study. GÖ conceived of the study, and participated in its design and coordination. All authors read and approved the final manuscript.

\section{Competing interests}

The authors declare that they have no competing interests.

Received: 13 August 2010 Accepted: 9 March 2011

Published: 9 March 2011

\section{References}

1. Piechalak A, Tomaszewska B, Baralkiewicz D, Malecka A: Accumulation and detoxification of lead ions in legumes. Phytochemistry 2002, 60:153-162. 
2. Sharma P, Dubey RS: Lead toxicity in plants. Braz I Plant Physiol 2005 17:35-52.

3. Ercal N, Gurer-Orhan H, Aykin-Burns N: Toxic metals and oxidative stress part I: mechanisms involved in metal-induced oxidative damage. Curr Top Med Chem 2001, 1:529-539.

4. Kirk TK, Farrell RL: Enzymatic "combustion": The microbial degradation of lignin. Ann Rev Microbiol 1987, 41:465-501.

5. Martinez AT: Molecular biology and structure-function of lignindegrading heme peroxidases. Enzyme Microb Technol 2002, 30:425-444.

6. Yetiş Ü, Dölek A, Dilek FB, Özcengiz G: The removal of Pb(II) by Phanerochaete chrysosporium. Water Res 2000, 34:4090-4100.

7. Iqbal M, Edyvean RGJ: Biosorption of lead, copper and zinc ions on loofa immobilized biomass of Phanerochaete chrysosporium. Miner Eng 2004, 17:217-223.

8. Li Q, Wu S, Liu G, Liao X, Deng X: Simultaneous biosorption of cadmium (II) and lead (II) ions by pretreated biomass of Phanerochaete chrysosporium. Sep Purif Technol 2004, 34:135-142.

9. Yetis U, Ozcengiz G, Dilek FB, Ergen N, Erbay A, Dolek A: Heavy metal biosorption by white-rot fungi. Water Sci Technol 1998, 38:323-330.

10. Huang $D L$, Zeng $G M$, Jiang $X Y$, Feng $C L$, Yu HY, Huang GH, Liu HL: Bioremediation of $\mathrm{Pb}$-contaminated soil by incubating with Phanerochaete chrysosporium and straw. J Hazard Mater 2006, 134:268-276.

11. Zeng $G$, Huang $D$, Huang $G, H u T$, Jiang $X$, Feng $C L$, Chen $Y N$, Tang $L$, Liu HL: Composting of lead-contaminated solid waste with inocula of white-rot fungus. Bioresour Technol 2007, 98:320-326.

12. Chen C, Wang J: Response of Saccharomyces cerevisiae to lead ion stress. Appl Microbiol Biot 2007, 74:683-687.

13. Ustun GE: Occurrence and removal of metals in urban wastewater treatment plants. J Hazard Mater 2009, 172:833-838.

14. Karvelas M, Katsoyiannis A, Samara C: Occurrence and fate of heavy metals in the wastewater treatment process. Chemosphere 2003, 53:1201-1210.

15. Abdel-Halim SH, Shehata AM, El-Shahat MF: Removal of lead ions from industrial waste water by different types of natural materials. Water Res 2003, 37:1678-1683.

16. Sthiannopkao $S$, Sreesai S: Utilization of pulp and paper industrial wastes to remove heavy metals from metal finishing wastewater. J Environ Manage 2009, 90:3283-3289.

17. Namasivayam C, Yamuna RT: Waste biogas residual slurry as an adsorbent for the removal of $\mathrm{Pb}$ (II) from aqueous solution and radiator manufacturing industry wastewater. Bioresour Technol 1995, 52:125-131.

18. Nesatyy VJ, Suter MJ: Proteomics for the analysis of environmental stress responses in organisms. Environ Sci Technol 2007, 41:6891-6900.

19. Washburn MP, Yates JR: Analysis of the microbial proteome. Curr Opin Microbiol 2000, 3:292-297.

20. Rabilloud T, Chevallet M, Luche S, Leize-Wagner E: Oxidative stress response: a proteomic view. Expert Rev Proteomics 2005, 2:949-956

21. Vido K, Spector D, Lagniel G, Lopez S, Toledano MB, Labarre J: A proteome analysis of the cadmium response in Saccharomyces cerevisiae. J Biol Chem 2001, 276:8469-8474

22. Hu Y, Wang G, Chen GY, Fu X, Yao SQ: Proteome analysis of Saccharomyces cerevisiae under metal stress by two-dimensional differential gel electrophoresis. Electrophoresis 2003, 24:1458-70.

23. Bae W, Chen X: Proteomic study for the cellular responses to $\mathrm{Cd} 2+$ in Schizosaccharomyces pombe through amino acid-coded mass tagging and liquid chromatography tandem mass spectrometry. Mol Cell Proteomics 2004, 3:596-607.

24. Gillet $\mathrm{S}$, Decottignies $\mathrm{P}$, Chardonnet $\mathrm{S}$, Le Maréchal P: Cadmium response and redoxin targets in Chlamydomonas reinhardtii: a proteomic approach. Photosynth Res 2006, 89:201-211.

25. Ozcan S, Yildirim V, Kaya L, Albrecht D, Becher D, Hecker M, Ozcengiz G: Phanerochaete chrysosporium soluble proteome as a prelude for the analysis of heavy metal stress response. Proteomics 2007, 7:1249-1260.

26. Gourlay CW, Ayscough KR: Actin-induced hyperactivation of the Ras signaling pathway leads to apoptosis in Saccharomyces cerevisiae. Mol Cell Biol 2006, 26:6487-501.

27. Hall PA, Russell SHE: The pathobiology of the septin gene family. J Pathol 2004, 204:489-505
28. Phillips AJ, Crowe JD, Ramsdale M: Ras pathway signaling accelerates programmed cell death in the pathogenic fungus Candida albicans. Proc Natl Acad Sci USA 2006, 103:726-731.

29. Shyu $A B$, Wilkinson MF: The double lives of shuttling mRNA binding proteins. Cell 2000, 102:135-138.

30. Chinnusamy V, Gong Z, Zhu JK: Nuclear RNA export and its importance in abiotic stress responses of plants. Curr Top Microbiol Immunol 2008, 326:235-255

31. Yang C, Carrier F: The UV-inducible RNA-binding protein A18 (A18 hnRNP) plays a protective role in the genotoxic stress response. J Biol Chem 2001, 276:47277-47284

32. Sakashita E, Tatsumi S, Werner D, Endo H, Mayeda A: Human RNPS1 and its associated factors: a versatile alternative pre-mRNA splicing regulator in vivo. Mol Cell Biology 2004, 24:1174-1187.

33. Linder P: Dead-box proteins: a family affair-active and passive players in RNP-remodeling. Nucleic Acids Res 2006, 34:4168-4180.

34. Briolat $\mathrm{V}$, Reysset $\mathrm{G}$ : Identification of the Clostridium perfringens genes involved in the adaptive response to oxidative stress. J Bacteriol 2002, 184:2333-2343.

35. Albrecht $D$, Guthke $R$, Brakhage AA, Kniemeyer O: Integrative analysis of the heat shock response in Aspergillus fumigatus. BMC Genomics 2010, 11:32

36. Nakamura T, Muramoto Y, Yokota S, Ueda A, Takabe T: Structural and transcriptional characterization of a salt-responsive gene encoding putative ATP-dependent RNA helicase in barley. Plant Sci 2004, 167:63-70.

37. Li D, Liu H, Zhang H, Wang $X$, Song F: OsBIRH1, a DEAD-box RNA helicase with functions in modulating defence responses against pathogen infection and oxidative stress. J Exp Bot 2008, 59:2133-2146.

38. Liu HH, Liu J, Fan SL, Song MZ, Han XL, Liu F, Shen FF: Molecular cloning and characterization of a salinity stress-induced gene encoding DEADbox helicase from the halophyte Apocynum venetum. J Exp Bot 2008, 59:633-644.

39. Dastoor Z, Dreyer JL: Potential role of nuclear translocation of glyceraldehyde-3-phosphate dehydrogenase in apoptosis and oxidative stress. J Cell Sci 2001, 114:1643-1453.

40. Weeks ME, Sinclair J, Butt A, Chung YL, Worthington JL, Wilkinson CRM, Griffiths J, Jones N, Waterfield MD, Timms JF: A parallel proteomic and metabolomic analysis of the hydrogen peroxide- and Sty1p-dependent stress response in Schizosaccharomyces pombe. Proteomics 2006, 6:2772-2796.

41. Magherini F, Tani C, Gamberi T, Caselli A, Bianchi L, Bini L, Modesti A: Protein expression profiles in Saccharomyces cerevisiae during apoptosis induced by $\mathrm{H}_{2} \mathrm{O}_{2}$. Proteomics 2007, 7:1434-1445.

42. Kim IS, Yun RS, Kwak SH, Jin IN: The physiological role of CPR1 in Saccharomyces cerevisiae KNU5377 against menadione stress by proteomics. J Microbiol 2007, 45:326-332.

43. Morigasaki S, Shimada K, Ikner A, Yanagida M, Shiozaki K: Glycolytic enzyme GAPDH promotes peroxide stress signaling through multistep phosphorelay to a MAPK cascade. Mol Cell 2008, 11:108-113.

44. Yang Y, Kwon HB, Peng HP, Shih MC: Stress responses and metabolic regulation of glyceraldehyde-3-phosphate dehydrogenase genes in Arabidopsis. Plant Physiol 1993, 101:209-216.

45. Baek D, Jin Y, Jeong JC, Lee HJ, Moon H, Lee J, Shin D, Kang CH, Kim DH, Nam J, Lee SY, Yun DJ: Suppression of reactive oxygen species by glyceraldehyde-3-phosphate dehydrogenase. Phytochemistry 2008, 69:333-338.

46. Carpentier SC, Witters E, Laukens K, Van Onckelen H, Swennen R, Panis B: Banana (Musa spp.) as a model to study the meristem proteome: acclimation to osmotic stress. Proteomics 2007, 7:92-105.

47. Varón D, Boylan SA, Okamoto K, Price CW: Bacillus subtilis gtaB encodes UDP-glucose pyrophosphorylase and is controlled by stationary-phase transcription factor sigma B. J Bacteriol 1993, 175:3964-3971.

48. Yan S, Tang Z, Su W, Sun W: Proteomic analysis of salt stress-responsive proteins in rice root. Proteomics 2005, 5:235-244.

49. Li L, Wright SJ, Krystofova S, Park G, Borkovich KA: Heterotrimeric G protein signaling in filamentous fungi. Annu Rev Microbiol 2007, 61:423-452.

50. Chen D, Toone WM, Mata J, Lyne R, Burns G, Kivinen K, Brazma A, Jones N, Bahler J: Global transcriptional responses of fission yeast to environmental stress. J Mol Biol Cell 2003, 14:214-229. 
51. Perfus-Barbeoch $L$, Jones AM, Assmann SM: Plant heterotrimeric G protein function: insights from Arabidopsis and rice mutants. Curr Opin Plant Biol 2004, 7:719-731

52. Joo JH, Wang S, Chen JG, Jones AM, Fedoroff NV: Different signaling and cell death roles of heterotrimeric $g$ protein $a$ and $b$ subunits in the arabidopsis oxidative stress response to ozone. The Plant Cell 2005, 17:957-970.

53. Suvarna K, Bartiss A, Wong B: Mannitol-1-phosphate dehydrogenase from Cryptococcus neoformans is a zinc-containing long-chain alcohol/polyol dehydrogenase. Microbiology 2000, 146:2705-2713.

54. Hondorp ER, Matthews RG: Oxidative stress inactivates cobalaminindependent methionine synthase (MetE) in Escherichia coli. PLoS Biol 2004, 2:e336.

55. Hohmann S: Osmotic stress signaling and osmoadaptation in yeasts. Microbiol Mol Biol Rev 2002, 66:300-372.

56. García-Leiro A, Cerdán ME, González-Siso Ml: Proteomic analysis of the oxidative stress response in Kluyveromyces lactis and effect of glutathione reductase depletion. J Proteome Res 2010, 9:2358-2376.

57. Reddy AM, Kumar SG, Jyonthsnakumari G, Thimmanaik S, Sudhakar C: Lead induced changes in antioxidant metabolism of horsegram (Macrotyloma uniflorum (Lam.) Verdc.) and bengalgram (Cicer arietinum L.). Chemospere 2005, 60:97-104.

58. Simpson JP, Di Leo R, Dhanoa PK, Allan WL, Makhmoudova A, Clark SM, Hoover GJ, Mullen RT, Shelp BJ: Identification and characterization of a plastid-localized Arabidopsis glyoxylate reductase isoform: comparison with a cytosolic isoform and implications for cellular redox homeostasis and aldehyde detoxification. J Exp Bot 2008, 59:2545-2554

59. Easton JA, Thompson P, Crowder MW: Time-dependent translational response of E. coli to excess Zn (II). J Biomol Tech 2006, 17:303-307.

60. Hwang EW, Kim KA, Park SC, Jeong MJ, Byun MO, Kwon HB: Expression profiles of hot pepper (Capsicum annuum) genes under cold stress conditions. J Biosci 2005, 30:657-667.

61. Kim YK, Yoo WI, Lee SH, Lee MY: Proteomic analysis of cadmium-induced protein profile alterations from marine alga Nannochloropsis oculata. Ecotoxicology 2005, 14:589-596.

62. Inui M, Suda M, Okino $S$, Nonaka $H$, Puskás LG, Vertes AA, Yukawa H: Transcriptional profiling of Corynebacterium glutamicum metabolism during organic acid production under oxygen deprivation conditions. Microbiology 2007, 153:2491-2504.

63. Singh R, Lemire J, Mailloux RJ, Appanna VD: A novel strategy involved anti-oxidative defense: The conversion of NADH into NADPH by a metabolic network. PLOS ONE 2008, 3:1-7

64. Kumari M, Taylor GJ, Deyholos MK: Transcriptomic responses to aluminum stress in roots of Arabidopsis thaliana. Mol Genet Genomics 2008, 279:339-357.

65. Marchitti SA, Brocker C, Stagos D, Vasiliou V: Non-P450 aldehyde oxidizing enzymes: the aldehyde dehydrogenase superfamily. Expert Opin Drug Metabol Toxico 2008, 4:697-720.

66. Parvatiyar K, Alsabbagh EM, Ochsner UA, Stegemeyer MA, Smulian AG, Hwang SH, Jackson CR, McDermott TR, Hassettl DJ: Global analysis of cellular factors and responses involved in Pseudomonas aeruginosa resistance to arsenite. J Bacteriol 2005, 187:4853-4864.

67. Bro C, Regenberg B, Lagniel G, Labarre J, Montero-Lomelí M, Nielsen J: Transcriptional, proteomic, and metabolic responses to lithium in galactose-grown yeast cells. J Biol Chem 2003, 278:32141-32149.

68. Sunkar R, Bartels D, Kirch H: Overexpression of a stress-inducible aldehyde dehydrogenase gene from Arabidopsis thaliana in transgenic plants improves stress tolerance. Plant J 2003, 35:452-464.

69. Kotchoni SO, Kuhns C, Ditzer A, Kirch HH, Bartels D: Over-expression of different aldehyde dehydrogenase genes in Arabidopsis thaliana confers tolerance to abiotic stress and protects plants against lipid peroxidation and oxidative stress. Plant Cell Environ 2006, 29:1033-1048.

70. Norbeck J, Blomberg A: Metabolic and regulatory changes associated with growth of Saccharomyces cerevisiae in $1.4 \mathrm{M} \mathrm{NaCl}$. Evidence for osmotic induction of glycerol dissimilation via the dihydroxyacetone pathway. J Biol Chem 1997, 272:5544-5554.

71. Boy-Marcotte E, Lagniel G, Perrot M, Bussereau F, Boudsocq A, Jacquet M, Labarre J: The heat shock response in yeast: differential regulations and contributions of the Msn2p/Msn4p and Hsf1p regulons. Mol Microbiol 1999, 33:274-283.
72. Rep M, Krantz M, Thevelein JM, Hohmann S: The transcriptional response of Saccharomyces cerevisiae to osmotic shock: Hot1p and Msn2p/Msn4p are required for the induction of subsets of high osmolarity glycerol pathway-dependent genes. J Biol Chem 2000, 275:8290-8300.

73. Godon C, Lagniel G, Lee J, Buhler JM, Kieffer S, Perrot M, Boucherie H, Toledano MB, Labarre J: The $\mathrm{H}_{2} \mathrm{O}_{2}$ stimulon in Saccharomyces cerevisiae. J Biol Chem 1998, 273:22480-22489.

74. Causton HC, Ren B, Koh SS, Harbison CT, Kanin E, Jennings EG, Lee TI, True HL, Lander ES, Young RA: Remodeling of yeast genome expression in response to environmental changes. Mol Biol Cell 2001, 12:323-337.

75. Inoue $Y$, Tsujimoto $Y$, Kimura A: Expression of the glyoxalase I gene of Saccharomyces cerevisiae is regulated by high osmolarity glycerol mitogen-activated protein kinase pathway in osmotic stress response. $J$ Biol Chem 1998, 273:2977-2983.

76. Wang $Y$, Cao YY, Jia XM, Cao YB, Gao PH, Fu XP, Ying K, Chen WS, Jiang YY Cap1p is involved in multiple pathways of oxidative stress response in Candida albicans. Free Radic Biol Med 2006, 40:1201-1209.

77. Espartero J, Sanchez-Aguayo I, Pardo JM: Molecular characterization of glyoxalase- 1 from a higher plant: upregulation by stress. Plant Mol Biol 1995, 29:223-1233.

78. Shiozaki N, Yamada M, Yoshiba Y: Analysis of salt-stress-inducible ESTs isolated by PCR-subtraction in salt-tolerant rice. Theor Appl Genet 2005, 110:1177-1186.

79. Lee DG, Ahsan N, Lee SH, Lee JJ, Bahk JD: Chilling stress-induced proteomic changes in rice roots. J Plant Physiol 2009, 166:1-11.

80. Sommer A, Fischer P, Krause K, Boettcher K, Brophy PM, Walter RD, Liebau E: A stress-responsive glyoxalase I from the parasitic nematode Onchocerca volvulus. Biochem J 2001, 353:445-452.

81. Gdula DA, Sandaltzopoulos R, Tsukiyama T, Wu C: Inorganic pyrophosphatase is a component of the Drosophila nucleosome remodeling factor complex. Gene Dev 1998, 12:3206-3216.

82. Schwanbeck R, Xiao H, Wu C: Spatial contacts and nucleosome step movements induced by the NURF chromatin remodeling complex. J Biol Chem 2004, 279:39933-39941.

83. Rodriguez-Gabriel MA, Remacha M, Ballesta JP: The RNA interacting domain but not the protein interacting domain is highly conserved in ribosomal protein P0. J Biol Chem 2000, 275:2130-2136.

84. Yacoub A, Kelley MR, Deutsch WA: Drosophila ribosomal protein P0 contains apurinic/apyrimidinic endonuclease activity. Nucl Acids Res 1996, 24:4298-4303.

85. Ji H, Moritz RL, Kim YS, Zhu HJ, Simpson RJ: Analysis of Ras-induced oncogenic transformation of $\mathrm{NIH}-3 \mathrm{~T} 3$ cells using differential-display 2-DE proteomics. Electrophoresis 2007, 28:1997-2008.

86. Yuan $X$, Kuramitsu $Y$, Furumoto $H$, Zhang $X$, Hayashi E, Fujimoto $M$, Nakamura K: Nuclear protein profiling of Jurkat cells during heat stressinduced apoptosis by 2-DE and MS/MS. Electrophoresis 2007, 28:2018-2026.

87. Singh OV: Proteomics and metabolomics: the molecular make-up of toxic aromatic pollutant bioremediation. Proteomics 2006, 6:5481-5492.

88. Zhao B, Poh CL: Insights into environmental bioremediation by microorganisms through functional genomics and proteomics. Proteomics 2008, 8:874-881.

89. Sharon A, Finkelstein A, Shlezinger N, Hatam I: Fungal apoptosis: function, genes and gene function. FEMS Microbiol Rev 2009, 33:833-854

90. Lorin S, Dufour E, Sainsard-Chanet A: Mitochondrial metabolism and aging in the filamentous fungus Podospora anserina. Biochim Biophys Acta 2006, 1757:604-610

91. Zamaraeva MV, Sabirov RZ, Maeno E, Ando-Akatsuka Y, Bessonova S, Okada Y: Cells die with increased cytosolic ATP during apoptosis: a bioluminescence study with intracellular luciferase. Cell Death Differ 2005, 12:1390-1397.

92. Rodrigues-Pousada CA, Nevitt T, Menezes R, Azevedo D, Pereira J, Amaral C: Yeast activator proteins and stress response: an overview. FEBS Letters 2004, 567:80-85

93. Vivancos AP, Jara M, Zuin A, Sansó M, Hidalgo E: Oxidative stress in Schizosaccharomyces pombe: different $\mathrm{H}_{2} \mathrm{O}_{2}$ levels, different response pathways. Mol Genet Genomics 2006, 276:495-502.

94. Prouty AL: Bench-scale development and evaluation of a fungal bioreactor for color removal from bleach effluents. Appl Microbiol Biotechnol 1990, 32:490-493. 
95. Damerval C, de Vienne D, Zivy M, Thiellement $H$ : The technical improvements in two-dimensional electrophoresis increase the level of genetic variation detected in wheat-seedling proteins. Electrophoresis 1986, 7:52-54.

96. Ramagli LS, Rodriguez LV: Quantitation of microgram amounts of protein in two-dimensional polyacrylamide gel electrophoresis sample buffer. Electrophoresis 1985, 6:559-563.

97. Görg A, Postel W, Günther S, Weser J, Strahler JR, Hanash SM, Somerlot L, Kuick R: Approach to stationary two-dimensional pattern: influence of focusing time and immobiline/carrier ampholytes concentrations. Electrophoresis 1988, 9:37-46.

98. Neuhof VN, Arold N, Taube D, Erhardt W: Improved staining of proteins in polyacrylamide gels including isoelectric focusing gels with clear background at nanogram sensitivity using Coomassie Brilliant Blue G250 and R-250. Electrophoresis 1988, 9:255-262.

99. Joint Genome Institutes (JGI) P. chrysosporium protein sequences database. [ftp://ftp.jgi-psf.org/pub/JG__data/Phanerochaete_chrysosporium/ v2.0/BestModels2.1.prot.gz].

100. MASCOT software. [http://www.matrixscience.com].

101. WoLF PSORT web server. [http://wolfpsort.seq.cbrc.jp].

doi:10.1186/1477-5956-9-12

Cite this article as: Yildırım et al: Characterization of proteome alterations in Phanerochaete chrysosporium in response to lead exposure. Proteome Science 2011 9:12.

\section{Submit your next manuscript to BioMed Central and take full advantage of:}

- Convenient online submission

- Thorough peer review

- No space constraints or color figure charges

- Immediate publication on acceptance

- Inclusion in PubMed, CAS, Scopus and Google Scholar

- Research which is freely available for redistribution

Submit your manuscript at www.biomedcentral.com/submit 